\title{
Reform and innovation of College Chinese Teaching under the "Internet plus" Background
}

\author{
Guodong Xue \\ College of Liberal Arts, Yulin University, Yulin, Shaanxi, China \\ 317950860@qq.com
}

Keywords: College Chinese; Teaching reform; Teaching mode; Teaching idea; Countermeasure

\begin{abstract}
With the national "Internet plus" action plan, the impact of the Internet on the way of people's life and work will further deepen. In the current increasingly emphasize the quality education of College Students under the atmosphere, the traditional "classroom centered, teacher centered and textbook as the main teaching content" closed, one-way transmission of College Chinese teaching mode, by the severe challenges from the open network environment, open learning concept and open learning tool. In the background of the opening of the network environment, we in the teaching of College Chinese courses, we must on the current teaching content and structure, teaching mode, teaching process, teaching methods and teaching assessment in the form of a series of links for bold reform and exploration.
\end{abstract}

\section{Introduction}

According to the July 2015 release of the thirty-sixth China Internet development statistics report shows that as of June, China's Internet users reached 668 million. The Internet from the original information acquisition and communication and entertainment needs, to the development of fusion and medical care, education, transportation and other public service depth of public services, also entered the field of politics, has really become a part of my life. At present, with the national "Internet plus" action plan, the impact of the Internet on the way of people's life and work will further deepen. [1-3]The most important feature of the Internet is open and interactive, the Internet can not only accommodate a large amount of information, and greatly enhance the dissemination of information and access efficiency.[4-6].

In the current increasingly emphasizes the cultivation of College Students' quality education and innovation ability of the atmosphere, the traditional "classroom centered, teacher centered and textbook as the main teaching content" closed, one-way transmission of College Chinese teaching mode, by the severe challenges from the open network environment, open learning concept and open learning tool. In the background of the current Internet plus, we in the teaching of College Chinese courses, we must keep pace with the times, in a timely manner to the current teaching content and structure, teaching mode, teaching process, teaching methods and examination form to carry out a series of reform and exploration of the corresponding link.

\section{Current Situation of College Chinese Teaching}

According to the Ministry of education in May 12, 2011, a Language Commission issued the "2010 China language situation report" pointed out: Chinese teenagers ability and writing ability is declining and degradation Chinese characters. In an era of rapid cultural transmission, our mother tongue is being forgotten, this is a sad. The marginalization of mother tongue education has led to the embarrassing situation in the teaching of Chinese language and literature:

At first, the marginalization of College Chinese curriculum. In the public course, the course of College Chinese does not have the authority of political thought course, but also lacks the restriction of English and computer grade examination. The deviation of education policy led to our students on language learning to ignore, the most obvious is the provisions of the students failed in English, college graduate, and to our mother tongue but do not set the appropriate threshold requirements. So, after entering the University, most of the students spend most of the time to learn English, but 
neglected our mother tongue learning. Now, similar to the "College Chinese" and "university writing" such a mother tongue teaching courses, in some of the university curriculum, seems to have faded out.

Second, the lack of interest in College Chinese courses. With the college students' employment pressure and survival pressure increasing, in order to seek a space for one person in the talent competition, college students have to strive for their proficiency in a particular line mainly in the curriculum, practical choice, for the mother tongue curriculum not interested in. Many students think they have learned more than a decade of Chinese, but also can not speak Chinese, can not write Chinese characters? It is generally believed that the study of Chinese has no substantial help to their employment, and the College Chinese is the "four" language. The Chinese language is equivalent to the middle school language, learning enthusiasm is greatly reduced. College Chinese courses have become a "liberal arts students despise science, science students do not love learning" a course.

\section{Methods and Materials}

In order to play the positive role of mobile Internet in College Chinese teaching, teachers need to apply the following teaching strategies:

Constructing an Effective Inquiry Learning Model based on the Learning Situation. College Chinese teaching design teachers to achieve the goal, to understand the students, students can enter the inner world. Cleverly designed to activate the students consciousness of inquiry. The College Chinese teaching based on mobile Internet needs to design the related learning activities according to the students' actual cognition level. When designing learning activities, teachers should understand what the students are most interested in, and what they need to do, so as to construct the most effective inquiry learning mode.

\section{Around the Theme, Statistics and Management of Information Resources.}

Based on the mobile Internet, the research on the College Chinese learning is more abundant than other teaching methods. University of the Chinese teachers in the new teaching mode is not merely a transfer of knowledge and information, they will face the multitude and students to the mobile Internet information resources. In order to enable students to explore the smooth development of learning, teachers must be related to the theme of information resources for statistical planning and management.

Provide Guidance on the Use of Mobile Networking and Inquiry Learning. The inquiry learning mode based on mobile Internet emphasizes the acquisition and utilization of Internet media information. However, the mobile Internet information resources multitude, dragons and fishes jumbled together is not easy for students to grasp the course. Teachers should be aware of the information resources on the Internet and provide guidance to students. Help students to obtain information and use information. Teachers can make a preliminary screening and resource list of mobile Internet information, so as to effectively guide students to use information resources.

Organize and Guide the Research and Communication on the Mobile Internet. In the inquiry based learning activities based on mobile Internet, students' online communication and inquiry become the key link of teaching activities. In the mobile Internet exchange, the students will be asked to study the needs of teachers, counseling and feedback related learning. Teachers should provide timely guidance according to the requirements of students. In the online collaboration, teachers still bear the burden of learning and guidance. In order to ensure the smooth communication between teachers and students, between students, teachers and students and other online Co-authors.

\section{Summary}

The role of mother tongue education in higher education can not be ignored. In the aspect of 
improving the comprehensive quality of college students, inheriting the Chinese culture, and promoting the humanistic spirit of the students, the course of College Chinese plays a very important role. By actively promoting the reform of College Chinese teaching, optimize the teaching content and structure, the reform of teaching mode, teaching process, teaching methods and optimize the evaluation mode reform and a series of reforms, the university language courses truly can not only improve the students' ability of literature appreciation, aesthetic ability and writing ability, and can promote the sustainable development of college students. A course to cultivate their lifelong learning ability.

\section{Acknowledgements}

This paper is a report of the research project of teaching reform in Yulin University.

\section{References}

[1] Xu Zhongyu. Chinese University [M]. Shanghai: East China Normal University press, 2007:1- 3

[2] Li Jingqiang. "College Chinese" discipline foundation and course orientation [J]. Journal of Henan Institute of Education, 2004 (2)

[3] Zhu Heng. The lightness of being unable to bear and the unbearable weight: on the academic orientation of College Chinese [J]. higher education research, 2009 (1)

[4] corona. [J]. Journal of Zhengzhou University investigation and analysis of the current situation of the ability of Chinese college students, 2007 (5).

[5] Cai Jigang. Research on the differences of College English teaching model between The University of Nottingham Ningbo and Fudan University [J]. China University of education, $2011(1)$

[6] Wang Fuyin, Zhang Baorong. A new exploration of the quality of higher education in China: an analysis of the mode of running a school in The University of Nottingham Ningbo [J]. China higher education, 2014 (3)

[7] Yang, $\mathrm{Xu}$ Nan, Wang small. The mother tongue education to strengthen college: a survey of more than ten universities at home and abroad based on the analysis of [N]. 2011- 01- 11 Guangming Daily.

[8] Peng. College Chinese should become an independent subject [N]. Chinese Social Science Journal, 2014- 7- 21 Liu Xiuling, Guo Xiaolu

[9] Implementation strategy of applied talents training in College Chinese course of non liberal arts [J]. Journal of Yangzhou University, 2014 (4)

[10]Zhou Jinsheng, Zhang Xiangping. The essence of the Chinese language and the way to reform [J]. education review, 2014 (7) 